\title{
Groove Location for Optimum Performance of Two-Lobe Bearing Using Genetic Algorithm
}

\section{Lintu Roy* and Kakoty SK}

Indian Institute of Technology Guwahati, Guwahati, India

\begin{abstract}
This paper presents the various arrangements of grooving location of two lobe oil journal bearing for optimum performance. An attempt has been made to find out the effect of different configurations of two lobe oil journal bearing by changing groove locations. Various groove angles that has been considered are $10^{\circ}, 20^{\circ}$ and $30^{\circ}$. The Reynolds equation is solved numerically in a finite difference grid satisfying the appropriate boundary conditions. Determination of Optimum performance is based on maximization of non dimensional load, flow coefficient and mass parameter and minimization of friction variable using Genetic Algorithm. The results using Genetic Algorithm are compared with Sequential quadratic programming (SQP). At optimum position there is a significant improvement in the optimum value of friction variable, flow coefficient, load and mass parameter value than that of two-lobe bearing with grooves position along horizontal direction and 1800 apart. The optimum groove locations arrived at are not diametrically opposite, which is the current practice. The present analysis is carried out and results are obtained for ellipticity ratio equal to 0.5 .
\end{abstract}

Keywords: Two lobe; Steady state; Stability characteristics

\section{Notation}

C Radial Clearance $(\mathrm{m})$

$D \quad$ Diameter of the Journal (m)

$L \quad$ Length of the Bearing $(\mathrm{m})$

$R \quad$ Bearing Radius (m)

e Eccentricity $(\mathrm{m})$

$\varepsilon \quad$ Eccentricity Ratio $=e / C$

$\left(\varepsilon_{1}, \varepsilon_{2}\right)$ Lobe Eccentricity Ratios

$\left(\phi_{1}, \phi_{2}\right)$ Attitude Angle of the Two Lobes

$\eta \quad$ Coefficient of Absolute Viscosity of the Lubricant (Pa-s)

$\mu, \bar{\mu}$ Coefficient of Friction, Friction Variable $=\mu(R / C)$

$N \quad$ Speed of the Journal in r. p. s

$\phi \quad$ Bearing Attitude Angle

$h \quad$ Film Thickness $(\mathrm{m})=C(1+\varepsilon \cos \theta)$

$\bar{h} \quad$ Non-Dimensional Film Thickness $=\frac{\mathrm{h}}{\mathrm{c}}$

$\begin{array}{lll}\theta_{1} & \theta_{2} & \text { Position of Starting of the Groove }\end{array}$

Position of End of the Groove

$U \quad$ Sliding Speed

$p_{\bar{p}} \quad \begin{aligned} & \text { Steady State Pressure }(\mathrm{Pa}) \\ & \quad \text { Non-Dimensional Steady State Pressure }=\frac{p C^{2}}{6 \eta U R}\end{aligned}$

$W \quad$ Load Carrying Capacity $(\mathrm{N})$

$\bar{W} \quad$ Non-Dimensional Load Carrying Capacity $=\frac{W C^{2}}{6 \eta U R^{2} L}$

$X \quad$ vertical Direction

Z Horizontal Direction

$W_{X} \quad$ Vertical Component (in X direction) of the resultant load

$W_{Z} \quad$ Horizontal Component (in $\mathrm{Z}$ direction) of the resultant load
$P \quad$ Load per unit bearing Area $=\frac{W}{D}$

$S \quad$ Somerfield Number $=\frac{\eta \mathrm{N}}{\mathrm{P}}\left(\frac{\mathrm{R}}{\mathrm{C}}\right)^{2}$

$\bar{q}_{z}$ Non Dimensional Flow Coefficient, $\left(\bar{q}_{z}=\frac{2 Q}{U L C}\right)$

$\bar{p} 1, \bar{p} 2 \quad$ Perturbed Pressures

$\varepsilon_{1}, \phi_{1} \quad$ Perturbed Eccentricity Ratio and Attitude Angle around the Steady State Value $\varepsilon_{0}, \phi_{0}$

$K_{X}, K_{Z}, K_{X}, K_{X} \quad$ Stiffness Coefficients (N/m)

$\bar{K}_{X}, \bar{K}_{Z}, K_{X}, \bar{K}_{X} \quad$ Non-dimensional stiffness co efficient= $\underline{\mathrm{KijC}}$ where $\mathrm{i}=\mathrm{X}, \mathrm{Z}$ and $\mathrm{j}=\mathrm{X}, \mathrm{Z}$

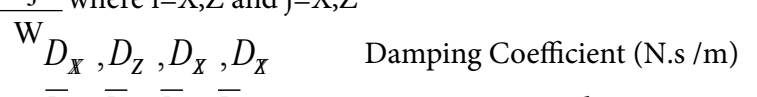

$\bar{D}_{\mathbb{X}}, \bar{D}_{Z}, \bar{D}_{\bar{X}}, \bar{D}_{\bar{X}} \quad$ Non-Dimensional Damping coefficient $=\frac{C_{i j} C \omega}{W}$ where $i=X, Z$ and $j=X, Z$

$t$ Time (s)

$\omega, \omega_{p} \quad$ Journal Rotational Speed $(\operatorname{Rad} / S)$, Frequency of Journal Vibration

$\tau$ Non-Dimensional time, $\tau=\omega_{\mathrm{p}} \mathrm{t}$

$\lambda \quad$ Whirl Ratio $=\omega_{p} / \omega$

$M, \bar{M}$ Rotor mass (kg), Mass Parameter, $\overline{\mathrm{M}}=\frac{\mathrm{MC} \omega^{2}}{\mathrm{~W}}$

( ) $\quad$ Steady State Value

*Corresponding author: Lintu Roy, Indian Institute of Technology Guwahati, Guwahati, India, 781309; E-mail: lintu@iitg.ac.in

Received August 13, 2015; Accepted September 01, 2015; Published September 06, 2015

Citation: Roy L, Kakoty SK (2015) Groove Location for Optimum Performance of Two-Lobe Bearing Using Genetic Algorithm. Int J Swarm Intel Evol Comput 4: 120. doi: 10.4172/2090-4908.1000120

Copyright: (c) 2015 Roy L, et al. This is an open-access article distributed under the terms of the Creative Commons Attribution License, which permits unrestricted use, distribution, and reproduction in any medium, provided the original author and source are credited. 


\section{Introduction}

Fluid-film journal bearings are available to support a rotating shaft in a turbo machinery system. A full circular journal bearing, on the other hand has a much simple configuration, but exhibits instability at higher rotational speeds. It is relatively inexpensive compared to the multilobe bearing. It is well known that whirl instability occurs at high speed in oil journal bearing. In order to improve the stability of a circular bearing, many researchers have tried to change its geometrical configuration by using, for example, pressure-dam bearing, elliptical bearing, and multi-lobe bearing. Present day bearings need to operate at over increasing speeds and loads, which confront the engineer with many new problems. Excessive power losses reduce the efficiency of the engine, high bearing temperature pose a danger to material of the bearing as well as the lubricant and instability, mainly in the form of oil whip, may ruin not only the bearing but the machine itself. New bearing designs are sought to meet the new requirements and these bearings are usually characterized by their non circular cross section. Almost any non circular bearing geometry will enhance shaft stability and under proper conditions this will also reduce power losses and increase oil flow (as compared to circular bearing), thus reducing bearing temperatures. In case of two-lobe bearings, usually lobes are separated by axial grooves of $20^{\circ}$ circumferential extensions. Two-lobe journal bearings are used in supporting the heavy rotors of turbo generators. Load per unit area on this type of bearing is high. The loading arc of a two lobe bearing is similar to lemon type bearing. A journal bearing which has an increased capacity to suppress instability is the elliptical bearing. This bearing looks like twoaxial groove bearing, but the two lobes are assembled so that their centre of curvature is not coincident. Each lobe has been displaced inward, this displacement expressed as a percentage of machined radial clearance, being denoted by preload or ellipticity. Large amount of ellipticity provide more sTable operation. Oscar Pinkus [1,2] was the first to study elliptical bearing including multilobe bearing. His work was on finite two lobe elliptical bearing with the numerical solution of Reynolds equation. In his work on elliptical bearing the nature of the oil flow, power loss was obtained for various $\mathrm{L} / \mathrm{D}$ ratios, ellipticities and various operating conditions. Singh et al. [3] using the variational approach analysed an elliptical bearing .Various data load, stiffness are compared with the available data. Lund et.al. [4] provided various data for two groove, elliptical and multilobe bearing in tabulated form. Later on Soni et al. [5] solved Reynolds equation by using Galerkin's technique of FEM for both laminar and turbulent flow region. Static and dynamic characteristics of two lobe bearing have been studied in terms of load support, oil flow, fluid stiffness and damping co-efficient and critical mass parameter. A comparative study of two lobe bearing configuration has been studied theoretically (both static and dynamic characteristics) by Kumar et al. [6]. From the comparison two lobe bearing configuration found to provides a good dynamic performance over a wide range of load conditions in comparison with elliptical and offset half bearing. Basavaraja et al. [7] studied the performance of a two lobe hole entry hybrid journal bearing system compensated by orifice section. In this paper Reynolds equation governing the flow of lubricant in the clearance space between journal and bearing together with flow through orifice restrictor has been solved with the use of FEM by Galerkin's method. Numerical results indicate that for two lobe symmetric hole entry hybrid bearing with an offset factor greater than one provides 30 to 50 percent larger of direct stiffness and damping coefficients as compared to circular symmetric hole entry hybrid journal bearing system.

Beasley et al. [9] in his paper presented the basic concepts of traditional genetic algorithm, its advantages with variety of applications. The paper also point out to advanced features and future directions. McCall [10] presented Genetic algorithms (GAs), a heuristic search and optimization technique inspired by natural evolution. GAs has been successfully applied to a wide range of real-world problems of significant complexity. Roy and Kakoty [12] presented the various arrangements of grooving location of two-groove oil journal bearing for optimum performance. An attempt has been made to obtain of different configurations of two groove oil journal bearing by changing groove locations. Various groove angles that have been considered are $10^{\circ}, 20^{\circ}$, and $30^{\circ}$. The Reynolds equation is solved numerically in a finite difference grid satisfying the appropriate boundary conditions. Determination of optimum performance is based on maximization of non-dimensional load, flow coefficient, and mass parameter and minimization of friction variable using genetic algorithm. The use of genetic algorithm, Neural Network, optimization of infiltration parameters has been discussed in various papers in [13-17]. When there are hundreds of publications on application of GAs, only couple of representative publications are cited here.

It has been observed that GAs have been successfully applied for optimizing bearing performance. However, performance of two-lobe oil journal bearing has not been optimized pertaining to location of groove positions with multiple objectives. In view of this, an attempt has been made in this paper to obtain an optimum configuration of the two lobe position around the circumference of the hydrodynamic journal bearing for maximum oil flow, minimum friction loss, maximum load bearing capacity and maximum critical speed vis-à-vis mass parameter, a function of speed.

It has been observed that various works that have been carried out include Numerical solution of Reynolds equation, steady state and dynamic characteristics of lobe bearings, stability analysis, comparison of the different characteristics of multi-lobe bearings etc.. It has been observed that no attempt has been made to find out the effect of different configurations on the performances of two lobe bearings by varying groove and lobe angles. In view of this, it is required to study the effect of different groove location on various design parameters like friction variable, flow rate, load carrying capacity and mass parameter. Further, it is also necessary to optimize the groove location of two-groove, two, three and four lobe bearings with single and multi objective functions.

\section{Theory}

\section{Geometry of two-lobe bearing}

Geometry and co-ordinate system for two-lobe bearing are shown in Figure 1 and Figure 2. In this present analysis, lobes are separated by

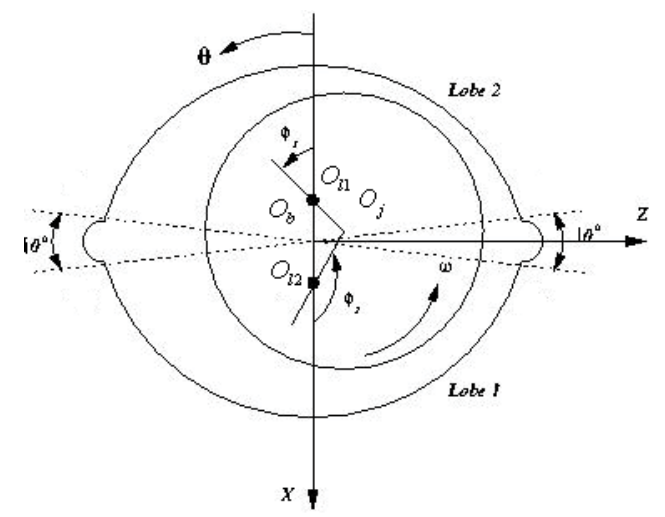

Figure 1: Geometry and co-ordinate system of 2 lobe bearing. 


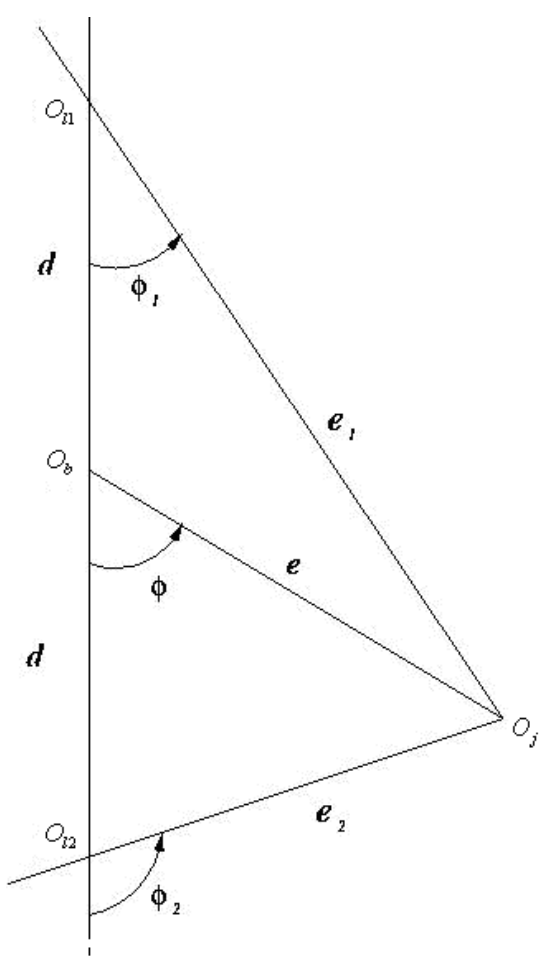

Figure 2: Lobe eccentricities and attitude angles of a 2 lobe bearing.

axial grooves of $10^{\circ}$ circumferential extensions for the provision of oil inlet in the journal bearing clearance area.

Two-lobe bearing is made up of two circular arcs each with its own centre of curvature $O_{l}$ displaced a distance'd' from the geometric centre of the bearing. In the present work two lobes of 170 degree arc each are separated by two axial oil grooves of $10^{\circ}$ extensions in horizontal direction. In Figure 2, geometry and co-ordinate system used for the analysis of two-lobe bearing is shown. For any given shaft position, lobe eccentricity ratios $\left(\varepsilon_{1}, \varepsilon_{2}\right)$ and attitude angles $\left(\phi_{1}, \phi_{2}\right)$ can be related with bearing eccentricity ratio $(\varepsilon)$, attitude angle $(\phi)$ and ellipticity ratio $(\delta)$ by simple trigonometric relations obtained from Figure 2 . In Figure 2 the journal center, bearing geometric center, center of the lobe 1 and center of the lobe 2 are represented by $\mathrm{O}_{\mathrm{j}}, \mathrm{O}_{\mathrm{b}}, \mathrm{O}_{11}$ and $\mathrm{O}_{12}$ respectively. From simple trigonometry, following relationships can be obtained

For lobe 1

$$
e_{1}^{2}=e^{2}+d^{2}-2 e d \cos (\pi-\phi)
$$

Dividing both sides by $c^{2}$, one gets,

$$
\varepsilon_{1}^{2}=\varepsilon^{2}+\delta^{2}+2 \varepsilon \delta \cos (\phi)
$$

$$
\text { Or } \quad \varepsilon_{1}=\sqrt{\varepsilon^{2}+\delta^{2}+2 \varepsilon \delta \cos \phi}
$$
where $\delta=\frac{d}{}$ is the bearing ellipticity ratio and $\varepsilon_{1}=\frac{e_{1}}{c}$ is the
eccentricity ratio $C_{0}$ lobe 1 .

$$
\begin{array}{ll}
\text { Also } & \tan \phi_{1}=\frac{e \sin \phi}{d+e \cos \phi} \\
\text { Or } & \phi_{1}=\tan ^{-1} \frac{\varepsilon \sin \phi}{\delta+\varepsilon \cos \phi} \\
\text { For lobe } 2 &
\end{array}
$$

$$
e_{2}^{2}=e^{2}+d^{2}-2 e d \cos \phi
$$

$$
\begin{aligned}
& \text { Or } \varepsilon_{2}=\sqrt{\varepsilon^{2}+\delta^{2}-2 \varepsilon \delta \cos \phi} \\
& \text { Where } \epsilon_{2}=\frac{e_{2}}{c} \text { is the eccentricity ratio of lobe } 2 . \\
& \text { Also } \tan \left(\pi-\phi_{2}\right)=\frac{e \sin \phi}{d-e \cos \phi} \\
& \phi_{2}=\pi-\tan ^{-1} \frac{\varepsilon \sin \phi}{\delta-\varepsilon \cos \phi}
\end{aligned}
$$

\section{Governing equation and non-dimensional parameters}

The governing equation is the Reynolds equation in two dimensions for an incompressible fluid. It can be written in the same non-dimensionless form as discussed in [12]. The pressure and film thickness equations can be perturbed for small amplitude of vibration and can be put in the Reynolds equation to obtain three differential equations in $\bar{p}_{0}, \bar{p}_{1}$, and $\bar{p}_{2}$

Stability margins are estimated for these bearings using linear perturbation method. The expressions for non dimensional flow coefficient, friction variables, load and mass parameters are disused in [12].

\section{Optimization Techniques}

\section{Objective functions and multi-objective problem formulation}

The problem is framed with four objectives. The variables used in the problem are in Case -I starting angle of first groove $\left(\theta_{l}\right)$, starting angle of second groove $\left(\theta_{2}\right)$.The optimum configurations obtained for an eccentricity ratio ranges from 0.05 to 0.451 in this case. In Case -II, the eccentricity ratio $(\varepsilon)$, starting angle of first groove $\left(\theta_{l}\right)$, starting angle of second groove $\left(\theta_{2}\right)$ are variables and acts as Chromosome, the groove angles being $10^{\circ}$ in both the cases. The objectives are minimization of friction variable $(\bar{\mu})$, maximization of load capacity $(\bar{W})$, flow coefficient $\left(\bar{q}_{Z}\right)$, maximization of mass parameter $(\bar{M}$ ), Objective function framing is same for both the cases and variable bounds are shown in Table 1.

The weighted sum strategy is used to convert the multi-objective problem of minimizing the objective vector into a scalar problem by constructing a weighted sum of all objectives. For two lobe bearing the objective function for minimization of a multi-objective function is formed by combining all the objectives as shown below:

$$
\text { Minimize } \begin{aligned}
f & =w_{1}\left[\bar{\mu} /\left(\bar{\mu}_{\max }-\bar{\mu}_{\min }\right)\right]+w_{2}\left[1-\bar{q}_{z} /\left(\bar{q}_{z \max }-\bar{q}_{z \min }\right)\right] \\
& \left.+w_{3}\left[1-\bar{w} /\left(\bar{w}_{\max }-\bar{w}_{\min }\right)\right]+w_{4}\left[1-\bar{M} /\left(\bar{M}_{\max }-\bar{M}_{\min }\right)\right)\right]
\end{aligned}
$$

Real coded Genetic algorithm procedure that has been applied in solving the problem of two lobe bearing is same as that has been applied for two-groove bearing as discussed in [12].

\section{Results and Discussion}

To ascertain the size of the groove for better performance, a comparison of non dimensional load is made for different groove

\begin{tabular}{|c|c|c|c|}
\hline Case & Variable & Lower Bound & Upper Bound \\
\hline \multirow{3}{*}{ I } & Starting angle of first groove & $0^{\circ}$ & $180^{\circ}$ \\
\cline { 2 - 4 } & Starting angle of second groove & $170^{\circ}$ & $350^{\circ}$ \\
\hline \multirow{3}{*}{ II } & $\mathcal{E}$ & 0.05 & 0.451 \\
\cline { 2 - 4 } & Starting angle of first groove & $0^{\circ}$ & $180^{\circ}$ \\
\cline { 2 - 4 } & Starting angle of second groove & $170^{\circ}$ & $350^{\circ}$ \\
\hline
\end{tabular}

Table 1: Variable bounds for the bearing problem. 
angles as shown in Table 2. It has been observed that the load carrying capacity is slightly higher with $10^{\circ}$ groove angles in comparison with $20^{\circ}$ $70^{\circ} 30^{\circ}$ groove angles (Table 2) in case of two lobe bearings. Therefore, $10^{\circ}$ groove angles are considered though out the analysis.

A code has been developed to calculate the steady state and dynamic characteristics for given values of $L / D$ ratios and different groove locations, which is subsequently used for obtaining optimum groove locations for different objective functions. An optimum groove location has been obtained depending on maximization of load, flow and mass parameter and minimization of friction with the help of Genetic Algorithm (GA) toolbox of MatLab. The obtained results from (GA) have been compared with the results obtained using Sequential quadratic programming (SQP).

The optimum value of fitness function obtained corresponding to maximization of flow coefficient has been tabulated for both GA and SQP in Table 3.

Similarly maximum load, minimum friction variable, maximum mass parameter values are also found to match for both the methods. It has been observed as stated above that the results using both the methods are found to be the same. However, GA has been used in this work as GA, being a heuristic search and optimization technique inspired by natural evolution, has been successfully applied to a wide range of real-world problems of significant complexity. It has been suggested that heuristic optimization provides a robust and efficient approach for solving complex real-world problems [10].

Initially a single objective function has been taken up. The generic algorithm convergence rate to true optima depends on the probability of crossover and mutation on one hand, and the maximum generation, on the other hand. In order to preserve a few very good strings, and rejecting low-fitness strings, a high crossover probability is preferred. The mutation operator helps to retain the diversity in the population,

\begin{tabular}{|c|c|c|c|}
\hline & \multicolumn{3}{|c|}{$\bar{W}$} \\
\hline$\varepsilon$ & $10^{\circ}$ groove & $20^{\circ}$ groove & $30^{\circ}$ groove \\
\hline 0.050 & 0.03802 & 0.0349 & 0.0318 \\
\hline 0.100 & 0.0799 & 0.07406 & 0.0681 \\
\hline 0.200 & 0.1822 & 0.170 & 0.1618 \\
\hline 0.350 & 0.458 & 0.440 & 1.107 \\
\hline 0.451 & 1.165 & 1.131 & 1.234 \\
\hline
\end{tabular}

Table 2: Comparison of non-dimensional load values using $10^{\circ}, 20^{\circ}$ and $30^{\circ}$ groove angles.

\begin{tabular}{|c|c|c|}
\hline \multirow{2}{*}{$\mathcal{E}$} & \multicolumn{2}{|c|}{$\begin{array}{c}\text { Objective function value } \\
\text { (Maximum flow coefficient) }\end{array}$} \\
\hline 0.050 & GA results & SQP results \\
\hline 0.100 & 16.916 & 16.8973 \\
\hline 0.150 & 18.305 & 18.305 \\
\hline 0.200 & 21.043 & 21.043 \\
\hline 0.239 & 22.401 & 22.401 \\
\hline 0.250 & 23.348 & 23.348 \\
\hline 0.260 & 23.607 & 23.607 \\
\hline 0.304 & 23.804 & 23.804 \\
\hline 0.350 & 24.916 & 24.916 \\
\hline 0.381 & 26.021 & 26.021 \\
\hline 0.451 & 26.719 & 26.719 \\
\hline & 28.300 & 28.300 \\
\hline
\end{tabular}

Table 3: Comparison of GA and SQP results. but disrupts the progress towards a converged population and interferes with beneficial action of the selection and crossover. Therefore, a low probability, 0.001-0.1, is preferred. The genetic algorithm updates its population on every generation, with a guarantee of better or equivalent fitness strings. For well-behaved functions, 30-40 generations are sufficient. For steep and irregular functions, 50-100 generations are preferred [8]. Considering these factors, a population size of 50, mutation probability of 0.1 and a cross over probability of 0.8 have been selected. The optimum results obtained for a particular value of eccentricity ratio for friction, flow coefficient, load, and mass parameter and combined objective function are shown in Figure 3 through Figure 7.

The results obtained and its comparison with groove position along horizontal direction and $180^{\circ}$ apart are tabulated below

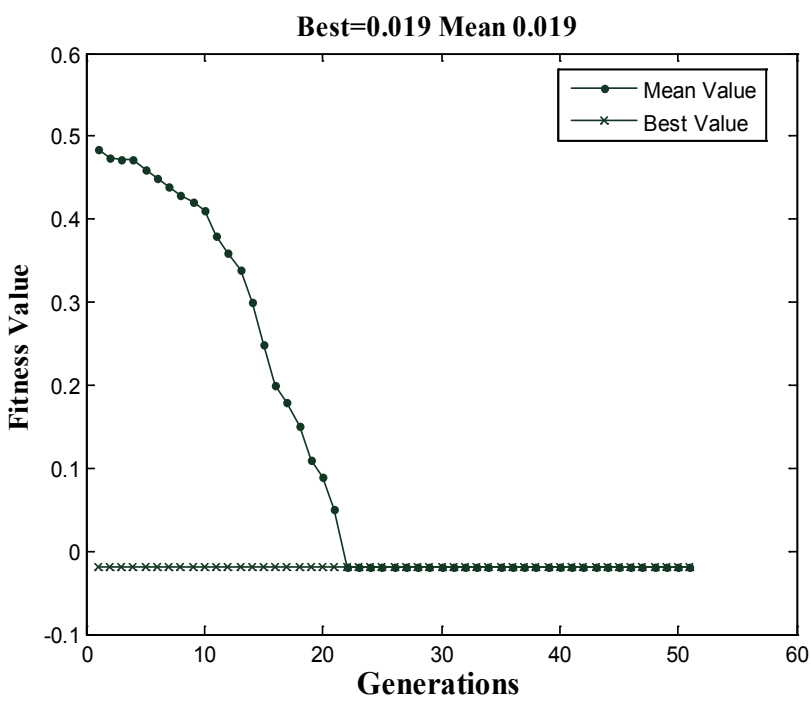

Figure 3: Fitness value considering friction variable as objective corresponding to an $\varepsilon=0.25$.

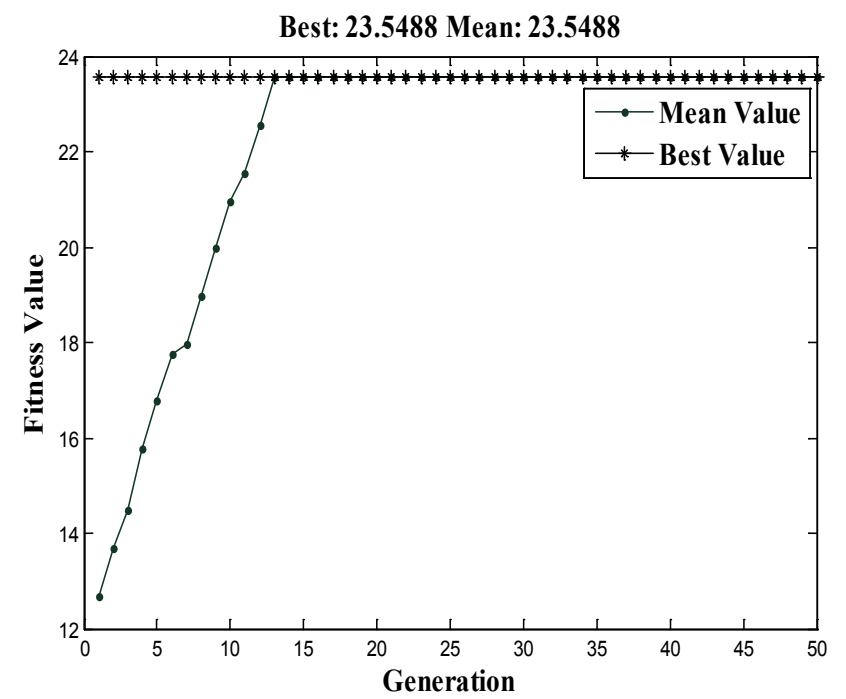

Figure 4: Fitness value considering flow coefficient as objective corresponding to an $\varepsilon=0.15$. 


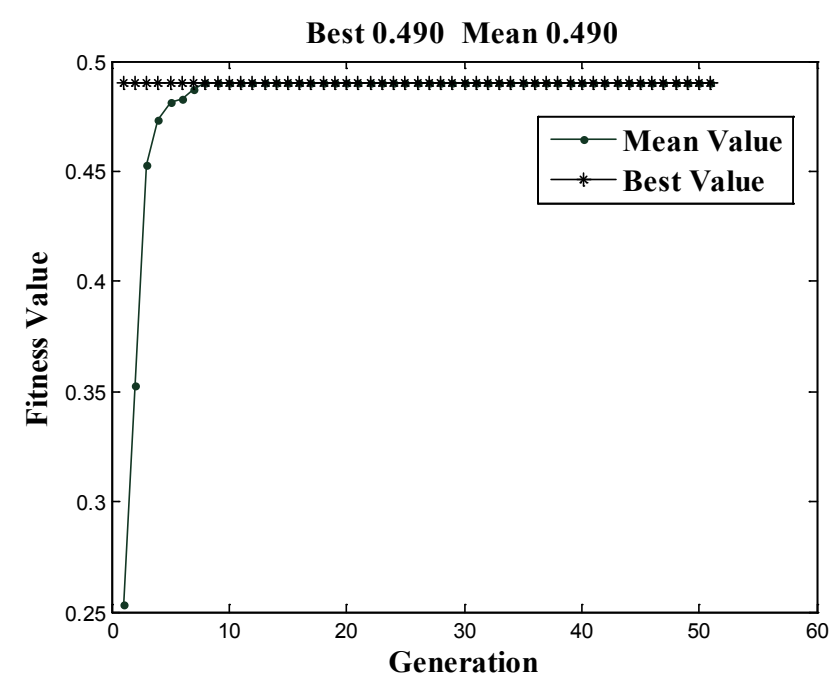

Figure 5: Fitness value considering load as objective function corresponding to an $\varepsilon=0.25$.

From the results shown in Table 5, it has been observed that first groove location remain near $0^{\circ}$, whereas the second groove location varies with eccentricity ratios in all the cases. Variations of the second groove location is different for different objective functions.

Similarly combining all the objective functions at a time the optimum configurations obtained is tabulated (Table 6).

It has been observed from the tabulated results in Table 6 that the staring position of the first groove at different eccentricity ratios for multi-objective function remain near to $0^{\circ}$, whereas second groove location varies for different eccentricity ratios. This indicates that second groove location is more sensitive compared to the first groove location.

If the three variables viz eccentricity $\operatorname{ratio}(\varepsilon)$, starting angles of the first groove $\left(\theta_{1}\right)$ and the second groove $\left(\theta_{2}\right)$ are taken as chromosome, then the optimum results obtained for friction, flow, load and mass parameter is shown in (Table 7).

From the above analysis, it has been observed that groove locations for various objective functions are different. The first groove varies between $0^{\circ}$ to $0.271^{\circ}$ and the second groove locations vary. From Table 8 it is observed that the corresponding groove location for objective function load capacity, mass parameter and all the combined objectives is nearly same.

The optimum results obtained for single objectives as well as multiobjective function has been discussed above. The optimum groove locations for different objective functions, viz., and maximization of non-dimensional load capacity, flow coefficient and mass parameter and minimization of friction variable have been obtained with the help of Genetic Algorithm (GA) toolbox of Mat Lab. It is observed that the optimum groove locations correspond to significant performance enhancement of two-lobe bearing.

\section{Determination of near to the optimum location of groove}

Only issue is that the groove positions are different for different eccentricity ratios as well as for different objective functions. Therefore, there is a need to identify the locations of grooves such that the performance characteristics are near to the optimum for any loading condition (eccentricity ratio) and any objective function. The manufacturers and designers will be immensely benefitted if such groove locations can be determined by some method. This issue is taken up in this section. The groove locations are rounded off to the nearest number eliminating the decimal places. The step by step procedure for finding out the near to optimum locations has been described below:

Procedure: The optimum configurations are different for different eccentricity ratios. Therefore, one such optimum configuration for a particular eccentricity ratio is applied for all other eccentricity ratios. The differences of objective function values for the optimum and the new configurations for all the eccentricity ratios are estimated and summed up. The other configurations are also tried in a similar manner. Finally the configuration which provides minimum differences of the summations is selected as the one 'near to optimum' configuration. An example for the objective function of minimum friction variable has been presented in Table 8 for better understanding of the procedure.

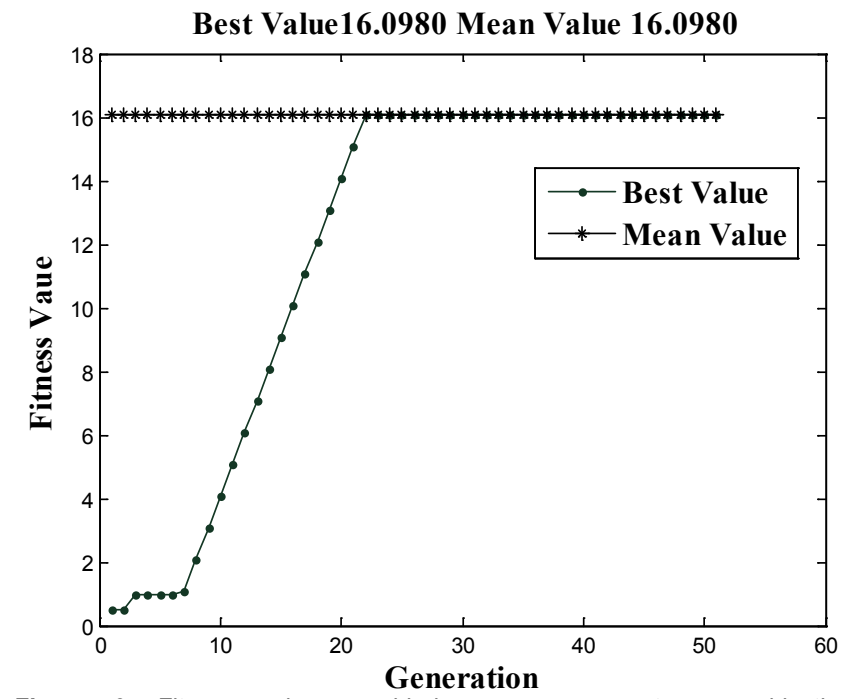

Figure 6: Fitness value considering mass parameter as objective corresponding to $\varepsilon=0.25$.

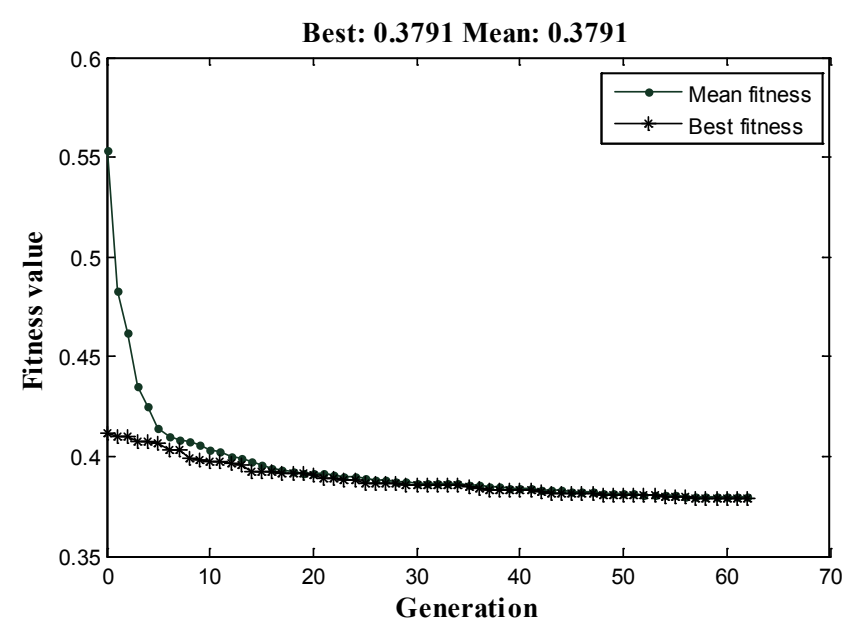

Figure 7: Fitness value for the combined objective above at $\varepsilon=0.15$. 
Citation: Roy L, Kakoty SK (2015) Groove Location for Optimum Performance of Two-Lobe Bearing Using Genetic Algorithm. Int J Swarm Intel Evol Comput 4: 120. doi: 10.4172/2090-4908.1000120

Page 6 of 8

\begin{tabular}{|c|c|c|c|c|}
\hline \multirow[b]{2}{*}{$\varepsilon$} & \multicolumn{4}{|c|}{ Non dimensional values in horizontal horizontal groove position } \\
\hline & $\mu(R / C)$ (optimumvalues) & Corresponding Optimum location & $\begin{array}{c}\bar{q}_{Z} \\
\text { (optimum values) }\end{array}$ & Corresponding Optimum location \\
\hline 0.050 & $0.401(0.012)$ & $\theta_{1}=1.957, \theta_{2}=180$ & $4.420(16.916)$ & $\theta_{1}=0.112, \theta_{2}=313.461$ \\
\hline 0.100 & $0.399(0.011)$ & $\theta_{1}=0.715, \theta_{2}=180$ & $4.569(20.868)$ & $\theta_{1}=0.273, \theta_{2}=345.082$ \\
\hline 0.150 & $0.396(0.002)$ & $\theta_{1}=0.075, \theta_{2}=180$ & $4.811(23.548)$ & $\theta_{1}=0.273, \theta_{2}=345.082$ \\
\hline 0.200 & $0.393(0.006)$ & $\theta_{1}=0.957, \theta_{2}=180$ & $5.136(20.868)$ & $\theta_{1}=0.273, \theta_{2}=345.082$ \\
\hline 0.239 & $0.390(0.011)$ & $\theta_{1}=1.987, \theta_{2}=180$ & $5.439(23.360)$ & $\theta_{1}=0.959, \theta_{2}=341.537$ \\
\hline 0.250 & $0.390(0.019)$ & $\theta_{1}=0.932, \theta_{2}=180$ & $5.531(20.868)$ & $\theta_{1}=0.273, \theta_{2}=345.082$ \\
\hline 0.260 & $0.389(0.022)$ & $\theta_{1}=1.000, \theta_{2}=180$ & $5.617(23.908)$ & $\theta_{1}=0.390, \theta_{2}=347.290$ \\
\hline 0.304 & $0.387(0.036)$ & $\theta_{1}=0.456, \theta_{2}=180$ & $6.012(24.830)$ & $\theta_{1}=0.152, \theta_{2}=340.679$ \\
\hline 0.350 & $0.388(0.050)$ & $\theta_{1}=0.824, \theta_{2}=180$ & $6.437(25.762)$ & $\theta_{1}=0.083, \theta_{2}=326.66$ \\
\hline 0.381 & $0.393(0.061)$ & $\theta_{1}=1.520, \theta_{2}=180$ & $6.704(26.725)$ & $\theta_{1}=0.273, \theta_{2}=345.082$ \\
\hline 0.451 & $0.457(0.082)$ & $\theta_{1}=0.890, \theta_{2}=180$ & $6.986(28.468)$ & $\theta_{1}=0.359, \theta_{2}=342.087$ \\
\hline
\end{tabular}

Table 4: Comparison of non-dimensional friction variable and flow coefficient values with groove position along horizontal direction and $180^{\circ}$ apart

\begin{tabular}{|c|c|c|c|c|}
\hline \multirow[b]{2}{*}{$\varepsilon$} & \multicolumn{4}{|c|}{ Non dimensional values in horizontal horizontal groove position } \\
\hline & $W$ (optimum values) & $\begin{array}{c}\text { Corresponding Optimum } \\
\text { location }\end{array}$ & $\begin{array}{c}\bar{M} \\
\text { (optimum values) }\end{array}$ & $\begin{array}{l}\text { Corresponding } \\
\text { Optimum location }\end{array}$ \\
\hline 0.050 & $0.037(0.181)$ & $\theta_{1}=1.000, \theta_{2}=180.000$ & $18.002(22.500)$ & $\theta_{1}=0.498, \theta_{2}=195.920$ \\
\hline 0.100 & $0.399(0.215)$ & $\theta_{1}=10.060, \theta_{2}=349.998$ & $11.591(15.001)$ & $\theta_{1}=0.498, \theta_{2}=195.920$ \\
\hline 0.150 & $0.127(0.290)$ & $\theta_{1}=11.670, \theta_{2}=349.964$ & $10.870(15.333)$ & $\theta_{1}=0.551, \theta_{2}=183.833$ \\
\hline 0.200 & $0.182(0.371)$ & $\theta_{1}=0.333, \theta_{2}=344.447$ & $11.530(15.800)$ & $\theta_{1}=0.938, \theta_{2}=204.882$ \\
\hline 0.239 & $0.233(0.460)$ & $\theta_{1}=3.856, \theta_{2}=349.348$ & $12.293(15.998)$ & $\theta_{1}=0.170, \theta_{2}=204.635$ \\
\hline 0.250 & $0.249(0.490)$ & $\theta_{1}=8.771, \theta_{2}=349.994$ & $12.590(16.098)$ & $\theta_{1}=0.950, \theta_{2}=183.822$ \\
\hline 0.260 & $0.265(0.516)$ & $\theta_{1}=8.228, \theta_{2}=349.989$ & $12.658(13.930)$ & $\theta_{1}=0.135, \theta_{2}=204.624$ \\
\hline 0.304 & $0.345(0.651)$ & $\theta_{1}=6.087, \theta_{2}=349.948$ & $13.686(15.160)$ & $\theta_{1}=0.367, \theta_{2}=184.317$ \\
\hline 0.350 & $0.458(0.842)$ & $\theta_{1}=3.183, \theta_{2}=349.898$ & $15.410(25.762)$ & $\theta_{1}=1.188, \theta_{2}=183.794$ \\
\hline 0.381 & $0.565(1.022)$ & $\theta_{1}=3.183, \theta_{2}=349.898$ & $18.279(26.725)$ & $\theta_{1}=1.370, \theta_{2}=183.55$ \\
\hline 0.451 & $1.137(1.810)$ & $\theta_{1}=3.63, \theta_{2}=344.730$ & $36.470(80.468)$ & $\theta_{1}=0.498, \theta_{2}=195.92$ \\
\hline
\end{tabular}

Table 5: Comparison of non-dimensional load and mass parameter results with groove position along horizontal direction and $180^{\circ}$ apart.

\begin{tabular}{|c|c|c|}
\hline$\varepsilon$ & $\theta_{1}$ & $\theta_{2}$ \\
\hline 0.05 & 0.631 & 247.413 \\
\hline 0.1 & 0.199 & 240.367 \\
\hline 0.15 & 0.017 & 253.776 \\
\hline 0.2 & 0.959 & 236.733 \\
\hline 0.239 & 0.477 & 234.469 \\
\hline 0.25 & 0.078 & 253.105 \\
\hline 0.26 & 0.496 & 245.539 \\
\hline 0.304 & 0.303 & 245.472 \\
\hline 0.35 & 0.97 & 242.806 \\
\hline 0.381 & 0.642 & 234.7 \\
\hline 0.451 & 0.441 & 202.063 \\
\hline
\end{tabular}

Table 6: The optimum configurations combining all the objective functions at a time.

\begin{tabular}{|c|c|c|c|}
\hline Optimum location for objectives & $\mathcal{E}$ & $\theta_{l}$ & $\theta_{2}$ \\
\hline Minimum friction variable & 0.094 & 2.989 & 323.625 \\
\hline Maximum flow & 0.271 & 1.489 & 180 \\
\hline Maximum load carrying capacity & 0.050 & 0 & 180 \\
\hline Maximum mass parameter & 0.375 & 0.099 & 180 \\
\hline Minimization of all the combined objectives & 0.450 & 0 & 180 \\
\hline
\end{tabular}

Table 7: Optimum location considering different objectives.

Since the summation of differences is small so any one of the two configurations are near to the optimum.

The near to optimum configurations for all the objective functions are presented in Tables 9 and 10.

\section{Conclusion}

From the results presented here, it can be inferred that the second groove location is sensitive to the type of objective function whereas the first groove is more or less same for any objective function. The practice and the notion of convenience of keeping groove positions $180^{\circ}$ apart need to be thoroughly looked into as the present results show that optimum groove locations are not $180^{\circ}$ apart for any of the objective functions considered in the present work. At optimum position there is a significant improvement in the performance characteristics, e.g., friction variable, flow coefficient, load and mass parameter value than that of two-lobe bearing with grooves position along horizontal direction and $180^{\circ}$ apart. Identification of the locations of grooves is done so that the performance characteristics are near to the optimum for any loading condition (eccentricity ratio) and any objective function and will be much beneficial to the manufacturers and designers. Experimental verification of the present result may lead to a new approach of production of bearings with optimum groove locations, however, it is beyond the scope of the present work and hopefully experimentalists have a problem in hand. 
Citation: Roy L, Kakoty SK (2015) Groove Location for Optimum Performance of Two-Lobe Bearing Using Genetic Algorithm. Int J Swarm Intel Evol Comput 4: 120. doi: 10.4172/2090-4908.1000120

Page 7 of 8

\begin{tabular}{|c|c|c|c|c|c|c|c|c|c|c|c|}
\hline \multirow[t]{2}{*}{$\mathcal{E}$} & \multicolumn{2}{|c|}{ Optimum configuration } & \multirow{2}{*}{$\begin{array}{c}\mu(R / C) \\
(1)\end{array}$} & \multicolumn{2}{|c|}{ Fixed configuration(1) } & \multirow{2}{*}{$\begin{array}{c}\mu(R / C) \\
(2)\end{array}$} & \multirow{2}{*}{$\begin{array}{c}\text { Difference } \\
(1-2)\end{array}$} & \multicolumn{2}{|c|}{ Fixed configuration(2) } & \multirow{2}{*}{$\begin{array}{c}\mu(\mathrm{R} / \mathrm{C}) \\
(3)\end{array}$} & \multirow{2}{*}{$\begin{array}{c}\text { Difference } \\
(1-3)\end{array}$} \\
\hline & $\theta_{1}$ & $\theta_{2}$ & & $\theta_{1}$ & $\theta_{2}$ & & & $\theta_{1}$ & $\theta_{2}$ & & \\
\hline 0.05 & 1 & 180 & 0.0125 & 0 & 180 & 0.148 & -0.1354 & 1 & 180 & 0.153 & -0.144 \\
\hline 0.1 & 0 & 180 & 0.0927 & & & 0.0927 & 0.0117 & & & 0.043 & 0.0497 \\
\hline 0.15 & 0 & 180 & 0.0904 & & & 0.216 & -0.086 & & & 0.209 & -0.1186 \\
\hline 0.2 & 0 & 180 & 0.006 & & & 0.358 & -0.3404 & & & 0.351 & -0.345 \\
\hline 0.239 & 1 & 180 & 0.033 & & & 0.453 & -0.4191 & & & 0.447 & -0.414 \\
\hline 0.25 & 0 & 180 & 0.0749 & & & 0.478 & -0.3884 & & & 0.473 & -0.3981 \\
\hline 0.26 & 1 & 180 & 0.0221 & & & 0.500 & -0.4779 & & & 0.495 & -0.451 \\
\hline 0.304 & 0 & 180 & 0.0368 & & & 0.589 & -0.5094 & & & 0.583 & -0.546 \\
\hline 0.35 & 1 & 180 & 0.049 & & & 0.67 & -0.531 & & & 0.665 & -0.616 \\
\hline 0.381 & 1 & 180 & 0.056 & & & 0.719 & -0.663 & & & 0.714 & -0.514 \\
\hline 0.451 & 0 & 180 & 0.083 & & & 0.811 & -0.726 & & & 0.811 & -0.728 \\
\hline \multicolumn{7}{|c|}{ Summation -4.2252} & \multicolumn{2}{|c|}{-4.264} & & & -4.225 \\
\hline
\end{tabular}

Table 8: Obtaining near optimum configuration from all the optimum configuration when objective function is friction variable.

Objective function

Minimization of friction variable

Maximization of flow coefficient

Maximization of load

Maximization of mass parameter

Minimization of a multi-objective function

\begin{tabular}{|c|c|}
\hline$\theta_{1}$ & $\theta_{2}$ \\
\hline 0 & 180 \\
\hline 0 & 345 \\
\hline 0 & 310 \\
\hline 0 & 204 \\
\hline 0 & 180 \\
\hline
\end{tabular}

Table 9: Near to the optimum configuration for different objectives.

\begin{tabular}{|c|c|c|c|c|c|c|c|c|c|c|}
\hline$\varepsilon$ & Results & s & $\phi$ & $\bar{K}_{X X}$ & $\bar{K}_{X Z}$ & $\bar{K}_{Z X}$ & $\bar{K}_{z Z}$ & $\bar{C}_{X X}$ & $\bar{C}_{X Z}=\bar{C}_{Z X}$ & $\bar{C}_{z z}$ \\
\hline \multirow{2}{*}{0.050} & Present & 1.450 & 93.910 & 38.470 & 22.750 & -22.120 & -1.240 & 79.210 & -28.090 & 18.60 \\
\hline & [4] & 1.442 & 93.910 & 38.580 & 22.650 & -22.140 & -1.290 & 79.050 & -28.140 & 18.60 \\
\hline \multirow{2}{*}{0.100} & Present & 0.690 & 93.120 & 18.790 & 11.210 & -10.730 & -0.200 & 38.540 & -12.860 & 9.360 \\
\hline & [4] & 0.698 & 93.120 & 18.930 & 11.250 & -10.790 & -0.240 & 38.730 & -12.970 & 9.400 \\
\hline \multirow{2}{*}{0.150} & Present & 0.440 & 91.970 & 12.184 & 7.460 & -6.830 & 0.260 & 24.970 & -7.450 & 6.342 \\
\hline & [4] & 0.442 & 91.970 & 12.280 & 7.450 & -6.870 & 0.260 & 25.000 & -7.500 & 6.360 \\
\hline \multirow{2}{*}{0.200} & Present & 0.300 & 90.370 & 8.855 & 5.540 & -4.762 & 0.580 & 17.860 & -4.480 & 4.800 \\
\hline & [4] & 0.308 & 90.370 & 8.930 & 5.580 & -4.790 & 0.580 & 17.990 & -4.500 & 4.820 \\
\hline \multirow{2}{*}{0.239} & Present & 0.230 & 88.800 & 7.240 & 4.660 & -3.670 & 0.770 & 14.420 & -2.910 & 4.020 \\
\hline & [4] & 0.240 & 88.800 & 7.310 & 4.700 & -3.700 & 0.770 & 14.540 & -2.930 & 4.040 \\
\hline \multirow{2}{*}{0.250} & Present & 0.220 & 88.280 & 6.950 & 4.510 & -3.430 & 0.820 & 13.740 & -2.550 & 3.860 \\
\hline & [4] & 0.224 & 88.280 & 6.870 & 4.490 & -3.410 & 0.820 & 13.680 & -2.510 & 3.850 \\
\hline \multirow{2}{*}{0.260} & Present & 0.210 & 87.790 & 6.570 & 4.320 & -3.180 & 0.880 & 12.990 & -2.170 & 3.680 \\
\hline & [4] & 0.213 & 87.790 & 6.650 & 4.360 & -3.210 & 0.860 & 13.090 & -2.230 & 3.700 \\
\hline \multirow{2}{*}{0.304} & Present & 0.170 & 87.790 & 5.830 & 3.980 & -2.610 & 1.080 & 11.320 & -1.240 & 3.440 \\
\hline & [4] & 0.161 & 83.290 & 5.630 & 3.840 & -2.320 & 1.010 & 10.750 & -1.020 & 3.070 \\
\hline \multirow{2}{*}{0.350} & Present & 0.120 & 81.800 & 4.940 & 3.520 & -1.510 & 1.140 & 9.020 & 0.001 & 2.490 \\
\hline & [4] & 0.120 & 81.800 & 4.990 & 3.540 & -1.520 & 1.140 & 9.040 & 0.010 & 2.490 \\
\hline \multirow{2}{*}{0.381} & Present & 0.090 & 78.650 & 4.760 & 3.440 & -1.010 & 1.220 & 8.230 & 0.580 & 2.110 \\
\hline & [4] & 0.097 & 78.650 & 4.820 & 3.460 & -1.010 & 1.210 & 8.260 & 0.560 & 2.100 \\
\hline \multirow{2}{*}{0.451} & Present & 0.040 & 63.700 & 6.160 & 3.810 & 0.171 & 1.400 & 7.890 & 1.580 & 1.170 \\
\hline & [4] & 0.045 & 63.700 & 6.250 & 3.830 & 0.190 & 1.400 & 7.880 & 1.560 & 1.160 \\
\hline
\end{tabular}

Table 10: Comparison of Steady state and dynamic characteristics of two-lobe journal bearing for $\frac{L}{D}=1$ with two $20^{\circ}$ axial grooves with $[4]$ for $L / D=1$ and $20^{\circ}$ axial groove for groove in the horizontal position and $180^{\circ}$ apart.

\section{Appendix}

For the purpose of validation of results the steady state characteristics of two lobe oil journal bearing having $20^{\circ}$ groove angles placed in horizontal position for $\mathrm{L} / \mathrm{D}=1$ are compared with published results [4] as shown in Table 8 . The present results are found to be fairly in good agreement with [4].

\section{References}

1. Pinkus Oscar (1956) Analysis of elliptical bearing. Transaction of ASME: 965973

2. Pinkus Oscar (1956) Power loss in elliptical and three lobe bearings Transaction 
Citation: Roy L, Kakoty SK (2015) Groove Location for Optimum Performance of Two-Lobe Bearing Using Genetic Algorithm. Int J Swarm Intel Evol Comput 4: 120. doi: 10.4172/2090-4908.1000120

of ASME 175: 899-904.

3. Singh DV, Sinhasan R, Kumar A (1977) A variational solution of two lobe bearing. Mechanism and Machine Theory 323-330.

4. Lund JW, Thomson KK (1978) A Calculation Method and Data for the Dynamic Coefficients of Oil Lubricated Journal Bearings. Proceedings of the ASME Design and Engineering Conference, Minneapolis 1.

5. Soni SC, Sinhasan R., Singh DV (1981) Performance characteristics of noncircular bearings in laminar and turbulent flow regimes. ASLE Transactions 24 : 29-41.

6. Kumar A, Sinhasan R, Singh DV (1983) A comparive study of some two lobe journal bearing configuration." ASLE Transactions 2:118-124

7. Basavaraja JS, Sharma SC, Jain SC (2008) Performance of an orifice compensated two lobe whole entry hybrid journal bearing. Advances in Tribology, 1-10.

8. Beasley David, David RB, Martin Ralph R (1993) an overview of genetic algorithms: Part 2, research topics, University computing, 25(4), 170-181.

9. McCall J (2005) Genetic Algorithms for Modelling and Optimisation, Journal of Computational and Applied Mathematics" 184: 205-222.
10. Hamrock BJ (1994) Fundamentals of film lubrication, Mc GrawHill, NewYork.

11. Roy L, Kakoty SK(2013 ) Optimum Groove Location of Hydrodynamic Journal Bearing Using Genetic Algorithm", Advances in Tribology 1-13.

12. Seyyed M, Behbahani SMR (2012) Comparison of Autoregressive Static and Artificial Dynamic Neural Network for the Forecasting of Monthly Inflow of Dez Reservoir. Journal of Environmental Sciences and Technology 13:1-14.

13. Valipour M, Montazar AA (2012) Sensitive Analysis of Optimized Infiltration Parameters n SWDC model" Advances in Environmental Biology 6: 2574-2581.

14. Valipour M, Montazar A.A (2012) An Evaluation of SWDC and WinSRFR Models to Optimize of Infiltration Parameters in Furrow Irrigation" American Journal of Scientific Research 69:128-142

15. Valipour M, Banihabib ME, Behbahani SMR.(2012) Monthly Inflow Forecasting using Autoregressive Artificial Neural Network. Journal of Applied Sciences 12: 2139-2147.

16. Valipour M, Banihabib ME , Behbahani SMR (2013) Comparison of the ARMA, ARIMA, and the autoregressive artificial neural network models in forecasting the monthly inflow of Dez dam reservoir. Journal of Hydrology 476: 433-441.
Citation: Roy L, Kakoty SK (2015) Groove Location for Optimum Performance of Two-Lobe Bearing Using Genetic Algorithm. Int J Swarm Intel Evol Comput 4: 120. doi: 10.4172/2090-4908.1000120 